\title{
Pais encarcerados: narrativas de presos sobre a experiência da paternidade na prisão
}

\author{
Márcia Lepiani Angelini Miranda \\ Tania Mara Marques Granato \\ Pontificia Universidade Católica de Campinas, SP, Brasil
}

\begin{abstract}
Resumo
Considerando o expressivo crescimento da população prisional brasileira e o fato do encarceramento impactar não apenas o indivíduo preso, mas também seus familiares, investigamos a experiência paterna de 41 presidiários cumprindo pena em uma penitenciária paulista. Optamos por uma abordagem qualitativa que utiliza uma Narrativa Interativa, seguida de uma discussão em grupo, para explorar os sentidos afetivo-emocionais que a experiência da paternidade pode tomar na prisão. Os filhos figuram como incentivo à mudança de vida do preso, além de serem referidos como principal suporte emocional nesta condição de vulnerabilidade. Sentimentos de culpa, impotência e arrependimento marcam o relato dos participantes, além da preocupação com o futuro dos filhos. Relações conjugais conflituosas e exigências institucionais contribuem para a fragilização do vínculo pai-filhos. Os achados deste estudo sinalizam os potenciais benefícios que o fortalecimento dos vínculos familiares reverte para o bem estar dos filhos e a reintegração social do preso.
\end{abstract}

Palavras-chave: Paternidade; Prisão; Narrativa interativa; Psicanálise.

\section{Imprisoned fathers: narratives of inmates about the experience of fatherhood in prison}

\begin{abstract}
Considering the growth of the Brazilian prison population and the fact that the imprisonment impacts not only the prisoner, but also their relatives, we investigate the paternal experience of 41 inmates serving time in a penitentiary of Sao Paulo. As a qualitative approach we used an Interactive Narrative followed by a group discussion, to explore the affective-emotional meanings that the experience of fatherhood may take in prison. The children are featured as an incentive to change the inmate's life, and as main emotional support in this condition of vulnerability. Feelings of guilt, impotence and regret set the tone for the participants' narratives, beyond the concern with their children's future. Contentious marital relationships and institutional demands contribute to weaken the father-son bond. This study indicates the potential benefits that the strengthening of familial bonds may revert to the well being of the children and to the social reintegration of the inmate.
\end{abstract}

Keywords: Fatherhood; Prison; Interactive narrative; Psychoanalysis.

\section{Padres encarcelados: narrativas de presos sobre la experiencia de la paternidad en la prisión}

\section{Resumen}

Considerando el expresivo crecimiento de la población penitenciaria brasileña y el hecho de que el encarcelamiento impacta el preso y sus familiares, hemos investigado la experiencia paterna de 41 prisioneros en una penitenciaria de São Paulo. Elegimos un abordaje cualitativo que utiliza una Narrativa Interactiva para explotar los sentidos afectivo-emocionales que la experiencia de la paternidad puede tener en la prisión. Los hijos representan un incentivo para el cambio de vida del preso y son el principal suporte emocional en esta condición de vulnerabilidad. Sentimientos de culpa, impotencia y arrepentimiento son frecuentes en el relato de los participantes, al lado de la preocupación con el futuro de los hijos. Relaciones conjúgales conflictivas y exigencias institucionales contribuyen para la fragilidad del vínculo padre-hijos. Este estudio señaliza los beneficios que el fortalecimiento de los vínculos familiares traen para el bien estar de los hijos e la reintegración social del preso.

Palabras clave: Paternidad; Prisión; Narrativa interactiva; Psicoanálisis. 
A população carcerária brasileira tem crescido a um ritmo acelerado. Dados do Departamento Penitenciário Nacional (DEPEN, 2015) revelam que entre os anos de 2000 e 2014 o número de pessoas privadas de liberdade aumentou $161 \%$, enquanto o crescimento total da população do Brasil foi de apenas $16 \%$ no mesmo período. São aproximadamente $608 \mathrm{mil}$ indivíduos encarcerados em todo o território nacional ${ }^{1}$, equivalendo a uma média de 300 presos para cada 100 mil habitantes. Esses números colocam o nosso país como detentor da quarta maior população carcerária do mundo, ficando atrás apenas dos Estados Unidos (2,2 milhões), China (1,7 milhão) e Rússia (674 mil), segundo os dados mais recentes do referido órgão.

Nesse panorama, podemos supor que seja cada vez maior o número de pais aprisionados e de filhos afetados pelo encarceramento paterno. Embora pesquisas recentes indiquem que a maioria dos indivíduos presos são pais (Lee, Sansone, Swanson, \& Tatum, 2012; Mapson, 2013; Ormeño, Maia, \& Williams, 2013), a paternidade no cárcere e sua repercussão familiar raramente são foco da atenção de legisladores, acadêmicos e instituições prisionais (Granja, Cunha, \& Machado, 2013; Hairston, 2001; McGrath, 2007). Os estudos que abordam a questão da parentalidade no cárcere ocupam-se, em sua maioria, do relacionamento entre mães encarceradas e seus filhos. $\mathrm{O}$ conceito de "pai recluso" é praticamente desconsiderado pelo sistema penal, e vem reforçar a ideia de que o cuidado infantil se restringe ao universo feminino (Granja et al., 2013).

Compreender as experiências de pais encarcerados é crucial para a preservação do bem estar e equilíbrio do próprio preso, de sua companheira, de seus filhos e da comunidade como um todo (Clarke et al., 2005; Codd, 2008; Hairston, 2002; Maldonado, 2006). Contudo, investigar essa experiência implica considerar o cenário familiar, prisional e social do recluso, assim como a articulação destes.

Vários estudos demonstram que para os presos que mantêm uma participação positiva e ativa na vida dos filhos antes da prisão, a reclusão altera por completo o envolvimento com a prole, em função do controle penal, com uma fragilização significativa do relacionamento entre pais e filhos (Edin et al., 2001; Granja et al., 2013; Houghton \& Navarro, 2014; Lanier, 1993). Tarefas parentais tradicionais relacionadas ao cuidado, proteção, disciplina e provisão costumam estar fora do alcance desses presos.

Contrariando o imaginário popular de que pais presos são indiferentes aos filhos e que nada proveem,

\footnotetext{
${ }^{1}$ Dados do sistema prisional, referentes a 30 de junho de 2014.
}

os estudos evidenciam que muitos desses pais mostramse interessados em manter uma relação estreita com seus filhos (Edin, Nelson, \& Paranal, 2001; Granja et al., 2013; Lanier, 1993; Lee et al., 2012; Silva, 2007). Contudo, na prisão, os homens não são encorajados a uma aproximação com sua prole, nem têm suporte para exercer o papel paterno, se assim o desejarem (Hairston, 2001).

$\mathrm{O}$ relacionamento entre pais e filhos durante o encarceramento costuma ser muito frágil (Hairston, 2001) e grande parte desses pais raramente veem seus filhos enquanto estão presos (Arditti et al., 2005; Maldonado, 2006; Mapson, 2013). Embora sejam inúmeras as razões para esse fenômeno, as barreiras institucionais não são as únicas responsáveis. Há que se levar em conta também as limitações pessoais e familiares dos detentos.

Sabe-se que as circunstâncias de vida de alguns pais presos, quando ainda estavam em liberdade, já eram geradoras de afastamentos familiares. Situações como o uso abusivo de drogas, histórico de violência, desemprego, relacionamentos amorosos instáveis e comportamento criminal não raramente permeiam a vida desses homens, distanciando-os das práticas parentais (Lee et al., 2012). Segundo estes autores, é possível imaginar que uma relação entre pais e filhos já tensa, ou pouco frequente, torne-se ainda mais complicada por uma ausência forçada.

Devemos também considerar a hipótese de que há pais no interior da prisão - assim como fora dela - que não desejam envolvimento com os filhos, recusandose a participar dos cuidados e educação (Hairston, 1998) e, por vezes, nem os reconhecendo como filhos. O grau de comprometimento de homens encarcerados com seus filhos pode variar entre ausente, parcialmente comprometido, ou presente (McGrath, 2007).

Em razão da importância atribuída às figuras parentais no desenvolvimento emocional saudável da criança (Winnicott, 1960/2007) e da relevância do suporte familiar para o equilíbrio mental do prisioneiro (Hairston, 2001; Mc Grath, 2007; Melo, 2013) é fundamental que todos os esforços se voltem para a preservação do vínculo familiar do homem encarcerado. Evidências empíricas sinalizam a importância da manutenção da relação entre pais presidiários e seus filhos (Lee et al., 2012; Maldonado, 2006; Mapson, 2013; Silva, 2007) para o bem estar de ambos, salvo quando houver algum impedimento, como riscos à saúde e à segurança da criança.

Enquanto estudos preliminares apontam o aprisionamento paterno como um fator de risco para o comportamento antissocial dos filhos (Hairston, 2001), outros argumentam que os laços familiares podem ser 
um fator de proteção contra a reincidência criminal (Clarke et al., 2005; Codd, 2008; Maldonado, 2006; Mapson, 2013). Além disso, a relação de proximidade com a prole durante o período de reclusão facilita o ajustamento do homem preso à vida institucional e diminui o risco de queixas somáticas, ansiedade e depressão (Lanier, 1993). Outras pesquisas sugerem que o contato com os filhos e o exercício das competências paternas no interior do cárcere facilitam o processo de reintegração do preso à sociedade, ao sair em liberdade (Dyer, 2005; Hairston, 2001; 2002; McGrath, 2007).

Os filhos também são beneficiados dessa relação, na medida em que se tornam menos propensos à delinquência juvenil, ao fracasso acadêmico e ao sofrimento emocional (Hairston, 2001; Maldonado, 2006; Mapson, 2013). Portanto, conforme defendem Lee et al. (2012), todos os envolvidos, sejam os pais presidiários, seus filhos, a instituição penal e a comunidade parecem se beneficiar dessa relação de proximidade.

Infelizmente, os efeitos do encarceramento se estendem para além do indivíduo preso, uma vez que seus familiares também sofrem as dores da prisão, ainda que não tenham cometido crime algum (Codd, 2008). O estigma social sofrido por toda a família, especialmente pelos filhos, acarreta muitas vezes sentimentos de vergonha e negação do vínculo familiar com o prisioneiro, como ressalta Oliveira (2010). Segundo Goffman (1982), o indivíduo que se relaciona socialmente com um estigmatizado, tende a ser considerado como sua extensão, compartilhando de seu descrédito.

Em virtude desse quadro complexo de vulnerabilidades a que detentos e seus familiares estão expostos, o presente estudo visa compreender a experiência de pais encarcerados com relação ao exercício da paternidade na prisão. Interessa-nos investigar os sentidos afetivo-emocionais que o preso atribui à relação entre pais e filhos em termos dos limites e possibilidades que o encarceramento paterno implica.

\section{Método}

Elegemos a abordagem qualitativa por ser particularmente adequada para o estudo de um fenômeno que é singular, pessoal e contextualizado (Stake, 2011), indo ao encontro das necessidades desta pesquisa, cuja ênfase recai sobre a singularidade da experiência paterna que tem lugar em um contexto prisional. Além disso, optamos por uma pesquisa qualitativa de inspiração psicanalítica devido ao seu potencial de apreensão e compreensão da experiência vivida pelos participantes em seu aspecto afetivo-emocional
(Granato \& Aiello-Vaisberg, 2011). Se o método psicanalítico pressupõe a narrativa do paciente como ponto de partida para a investigação do drama vivido, torna-se coerente com a proposta psicanalítica de pesquisa que utilizemos neste estudo um procedimento narrativo que maximize a possibilidade de expressão imaginativa dos participantes, em detrimento de racionalizações como respostas defensivas.

A Narrativa Interativa (NI) consiste de uma breve história ficcional criada pelo pesquisador, de modo a apresentar uma questão, situação ou conflito que é objeto de investigação científica, convidando os participantes a completar aquela trama de forma livre e espontânea rumo a um desfecho (Granato \& Aiello-Vaisberg, 2013). O envolvimento emocional do participante só será possível caso a história guarde íntima relação com a vida concreta e, dessa forma, permita que o participante se identifique com os personagens e seus dramas. Além disso, esse tipo de procedimento protege o participante de uma exposição direta a vivências emocionais perturbadoras, na medida em que dosa o acesso à realidade do vivido pela via da ficção.

A fim de analisar as experiências de pais encarcerados, elaboramos a seguinte Narrativa Interativa (NI) a qual procurou refletir elementos do cotidiano dos participantes no ambiente prisional, tendo como base a experiência profissional de uma das pesquisadoras:

"Era domingo bem cedo e a agitação no pavilhão já era grande. Tudo deveria estar limpo e arrumado para receber os visitantes que logo começariam a chegar. Aquele não era um domingo igual aos outros, era o Dia dos Pais. Depois do café, enquanto alguns companheiros davam os últimos retoques nos preparativos para a festa, e outros já aguardavam a abertura dos portões, Carlos se sentou num canto, tirou do bolso uma foto de seus filhos e passou a olhá-la fixamente. Nesse instante, ele começou a pensar muitas coisas..."

Participaram deste estudo, em caráter voluntário, 41 presidiários adultos do sexo masculino, cuja única condição para ser incluído no estudo era o fato de ser pai, independentemente de sua idade, escolaridade, raça, religião, tempo de pena ou tipo de delito. Eles estavam cumprindo pena em uma penitenciária do interior paulista, a qual à época da coleta de dados abrigava 1947 presos em regime fechado. A faixa etária dos participantes variou de 21 a 66 anos, sendo que 20 entrevistados (48\%) tinham idade entre 21 e 35 anos. Em relação à escolaridade, $43 \%$ dos participantes declarou ter ensino fundamental incompleto, indo ao 
encontro do perfil da população prisional brasileira. Informações como tempo de pena e tipo de crime não foram solicitados em razão do presente estudo não ter o objetivo de estabelecer qualquer relação entre esses dados e as questões familiares. Apesar disso, esclarecemos que os crimes da maioria dos reclusos desta unidade prisional estão de alguma forma relacionados a drogas ilícitas.

Este estudo atendeu aos procedimentos éticos exigidos para pesquisa envolvendo seres humanos, conforme Resolução 466/2012 do Conselho Nacional de Saúde. O mesmo foi aprovado pelos Comitês de Ética da Pontifícia Universidade Católica de Campinas, sob Parecer $\mathrm{n}-1.285 .239$ e da Secretaria da Administração Penitenciária (SAP), sob Parecer n⿳o 1.301.524, além da Autorização Judicial do MM Juiz de Direito do Deecrim da 4a RAJ Campinas: Expediente de Corregedoria no 353/2015.

Como estratégia de aproximação dos participantes, elaboramos um folheto-convite com as informações básicas da pesquisa, incluindo o contexto e os objetivos da mesma, que foi distribuído aos interessados no pátio da unidade prisional por um funcionário da instituição, após uma breve explanação sobre o tema da pesquisa. Aos voluntários caberia apenas o preenchimento do panfleto com o nome e a manifestação inicial de interesse de participar, e sua devolução ao funcionário responsável, que os repassaria para uma das pesquisadoras. Optamos pela intermediação do funcionário nesta primeira aproximação dos participantes para que se sentissem livres para optar, o que poderia não ocorrer na presença da pesquisadora que é funcionária na unidade prisional.

Finalizada esta etapa, os participantes voluntários - que superaram nossa expectativa e tiveram que ser selecionados aleatoriamente por sorteio - foram chamados em quatro grupos de encontro único, para participar de uma entrevista coletiva com a pesquisadora, em sala e horário reservados para esta atividade, na própria penitenciária, onde receberam esclarecimentos detalhados sobre os objetivos da pesquisa, seu método e os cuidados éticos envolvidos. Entendemos que dividir os participantes em grupos menores proporcionaria uma melhor acolhida e um maior envolvimento dos participantes, além de promover uma escuta mais sensível por parte da pesquisadora.

Após a elucidação dos procedimentos, os participantes assinaram o Termo de Consentimento Livre e Esclarecido (TCLE) e, na sequência, foram convidados a completar a NI por escrito. Como segunda fase do procedimento, foi proposto um momento de discussão em grupo sobre o tema da paternidade, a partir dos sentimentos desencadeados pela história e pelas vivências pessoais dos participantes. Esta etapa buscou dar continuidade à produção associativa de sentidos afetivo-emocionais, ampliando as possibilidades de expressão dos participantes sobre um tema que os toca sobremaneira, vale dizer o exercício da paternidade na prisão.

Como forma de registro, após cada encontro grupal, a pesquisadora responsável pela coleta de dados elaborou um relato, denominado de Relato do Encontro (RE), a fim de registrar as associações dos participantes, a dinâmica interpessoal do encontro e suas impressões contratransferenciais. Esses grupos foram identificados como A, B, C e D. As 41NI e os quatro RE compuseram o corpus desta pesquisa, sendo tomados posteriormente para consideração psicanalítica, com o objetivo de identificar os sentidos atribuídos pelos participantes à experiência da paternidade na prisão. Tendo em vista o refinamento das interpretações e as exigências de rigor na pesquisa, todas as interpretações foram discutidas na interlocução com o grupo de pesquisa, satisfazendo a exigência metodológica de triangulação (Stake, 2011). Finalmente, nossos achados foram discutidos à luz de pesquisas contemporâneas sobre o tema da paternidade no cárcere, tendo como pano de fundo as contribuições de Donald Winnicott (1960/2007) sobre a provisão ambiental.

\section{Resultados e Discussão}

O material de pesquisa disponível para análise interpretativa foi composto de 45 narrativas, sendo 41 NI completadas por escrito pelos participantes e quatro RE elaborados pela pesquisadora responsável, sendo um relato por grupo. Esclarecemos que os nomes citados no presente artigo são fictícios e não correspondem efetivamente aos apenados participantes. Para facilitar a compreensão do leitor, assinalamos que ao mencionarmos no texto as produções escritas nas NI, utilizaremos como identificador do material apenas o número que lhe foi atribuído, seguido da letra do grupo ao qual o pai encarcerado estava inserido, uma vez que as NI são completadas anonimamente. Por outro lado, ao nos referirmos às falas dos participantes durante o grupo de discussão, faremos uso de nomes fictícios para facilitar a compreensão do leitor, e não para tecer relações entre as duas produções narrativas (escrita e oral).

Como primeiro achado verificamos que a NI elaborada para este estudo demonstrou ser um recurso de fácil aplicação e compreensão pelos participantes, além de permitir a identificação dos participantes com o protagonista da história e seu contexto dramático, 
tornando-se potencialmente geradora de sentidos pessoais (Granato \& Aiello-Vaisberg, 2016). Colocações dos participantes, como: "Esse Carlos aí sou eu, e essa história que eu escrevi é a história da minha vida" (Elias, Grupo C), ou "A senhora quase me fez chorar escrevendo essa história... foi como um filme passando na minha cabeça... muitas lembranças dos meus filhos" (Saul, Grupo B) atestam seu potencial heurístico.

Os participantes deste estudo revelaram que suas experiências não são consonantes nem uniformes, mas complexas e multideterminadas. Seus relacionamentos e históricos parentais se mostraram bastante diversificados, indo ao encontro dos achados de Clarke et al. (2005). Percebe-se que o estilo de vida pré-encarceramento de muitos desses homens tem um grande impacto em suas relações interpessoais atuais e na forma com que exercem suas competências paternas.

Quanto às relações familiares, encontramos entre os participantes vários relatos de instabilidade conjugal, sendo seus filhos oriundos de diversos relacionamentos, o que vem a corroborar os dados de Hairston (1998), Mapson (2013) e McGrath (2007). Alguns se mostraram afetivamente ligados a crianças e adolescentes que não eram seus filhos biológicos. O modelo da família nuclear tradicional - pais casados, que vivem juntos, com filhos biológicos - foi dificilmente retratada pelos participantes.

$\mathrm{Na}$ esfera do relacionamento paterno-filial, a maioria dos pais entrevistados referiu vínculos frágeis com os filhos, tendo pouco ou nenhum contato com eles durante o encarceramento, confirmando as conclusões de Arditti et al. (2005), Houghton e Navarro (2014) e Mumola (2000). Apesar disso, muitos participantes do nosso estudo afirmaram o desejo de estreitar os laços familiares, em conformidade com Hairston (1998) e Lee et al. (2012). Uma das NI evidenciou esse sentimento:

"Muitas pessoas acham que um reeducando não se lembra dos seus filhos neste lugar, mas mal sabe que todos seres humanos são feitos da mesma carne. Só quem vive e sente a falta de um filho ou de um enteado sabe o quanto dói." (NI 7 Grupo D)

A natureza precária dos relacionamentos entre pais e filhos é atribuída em grande parte à existência de um histórico criminal e de laços familiares rompidos ou prejudicados, especialmente com as mães das crianças, com quem costumam manter uma relação mais conflituosa que cordial (Hairston, 2001; Lee et al., 2012). As seguintes vinhetas exemplificam essa questão: "a mãe dos meus filhos não deixaria eles virem, por tudo que já passamos no passado, por tudo que eu aprontei, por ter deixado ela sozinha..."
(Rodolfo, Grupo D), ou "a mãe dela nunca deixaria ela vir me ver em um presídio. Ela acha que aqui é um lugar de monstro sem recuperação" (NI 1 Grupo B).

Os relatos sugerem que a atitude da mãe é essencial na facilitação do relacionamento entre o pai encarcerado e seus filhos, pois cabe a ela autorizar as visitas na prisão e/ou intermediar a correspondência entre eles. Os estudos de Arditti et al. (2005), Boswell e Wedge (2002), Clarke et al. (2005) e Hairston (2001) sustentam essa conclusão, e apontam para o fato de que as mães desempenham um papel crítico na aproximação ou no distanciamento afetivo entre pais e filhos.

As exigências institucionais também foram referidas pelos participantes como um fator disruptivo do vínculo entre pais reclusos e seus filhos, tais como o constrangimento das revistas e as longas filas que as antecedem. Além disso, a distância geográfica entre a unidade prisional e a residência dos familiares, somada à dificuldade financeira da maioria dos visitantes, acabam contribuindo para que o contato e o envolvimento dos reclusos com sua família diminuam com o passar do tempo, representando uma considerável ameaça para a manutenção dessas famílias, conforme assinala Lanier (1993). Vejamos alguns relatos: "... me trouxeram para esta região e tudo ficou muito, muito mais difícil. Moro no litoral sul de XXXX..." (NI 8, Grupo A) e “... a distância dificulta muito a relação com o filho... parece que vai esfriando aquele contato" (Eli, Grupo B).

Alguns presos optam pelo afastamento dos filhos do espaço prisional como forma de cuidado e proteção. Em consonância com os estudos de Boswell e Wedge (2002), Clarke et al (2005), McGrath (2007) e Silva (2007), muitos participantes percebiam o ambiente carcerário como inerentemente hostil a crianças e adolescentes, preferindo desencorajar as visitas, com o objetivo de evitar a exposição dos filhos a situações de risco, especialmente no que se refere ao impacto emocional. Um dos pais participantes do nosso estudo recordou a experiência de, ainda criança, ter acompanhado a mãe em uma visita ao irmão que estava preso. Concluiu que aquelas imagens o marcaram profundamente: "Não quero isso para o meu filho. O ambiente é opressor... Pode gerar traumas na criança." (Pedro, Grupo B). Outra produção narrativa refere o impacto negativo da visita sobre os filhos: "porque é mesmo um dano irreparável para a criança. Ela tem que passar pela revista, ficar sem roupa, agachar... É muita humilhação... Fora ver o pai preso... acho que isso marca para sempre a cabeça da criança" (Gilmar, Grupo A).

Alguns participantes avaliam que, devido à constante exposição, as crianças e/ou adolescentes podem se acostumar ao ambiente da prisão, aceitando o encarceramento como um fenômeno natural, risco 
apontado por Hairston (2002) e Mc Grath (2007): “Tem criança que vem e é como se estivesse numa creche... fica ali jogando bola... não acho isso bom, ela tem que saber que isso aqui é um lugar de sofrimento, de dor... para nunca cair nisso aqui" (Ozorio, Grupo B).

Vários participantes referem o risco de que os filhos passem a admirar os criminosos no interior do presídio, tomando-os como modelo a ser seguido. Segundo Aníbal (Grupo D) "se na rua já tem esse problema (admirar bandidos), imagina aqui dentro". Além dessa inversão de valores sociais, Aníbal (Grupo D) ressaltou que a prisão é um lugar perigoso e instável: "Na cadeia uma hora está tudo bem, daqui a pouco pode não estar... Esses dias mesmo começou uma confusão lá no raio, no dia de visita, como é que a gente vai prever isso?"

$\mathrm{O}$ sofrimento emocional que marca o encontro entre pais e filhos na prisão é outro motivo para que prisioneiros desencorajem as visitas da família, opção também observada nos estudos de Arditti et al. (2005), Boswell e Wedge (2002), Maldonado (2006), Mapson (2013) e McGrath (2007). A emoção vivida no momento da despedida parece ser um dos aspectos mais difíceis de lidar: "na hora da visita é tudo maravilhoso, mas na hora de ir embora a tristeza bate. E é pior ainda pra quem fica, porque fica vários dias com aquele aperto no coração" (Miguel, Grupo A). Outra narrativa confirma que "a pior coisa é na hora de ir embora, porque ela (a filha) fica pedindo: deixa eu dormir com você hoje, pai ?" (Armando, Grupo B).

Em sintonia com os achados de Clarke et al. (2005), nossos participantes assinalaram que, embora as visitas sejam muito esperadas pelos pais encarcerados, na medida em que proveem o contato direto entre presos e familiares, as tensões institucionais e familiares frequentemente prejudicam o seu desfrute. Para alguns homens privados de liberdade, a vergonha de estar na prisão pode ser uma das razões para que um pai prefira manter distância dos filhos, segundo Clarke et al. As palavras de Abner (Grupo A) expressam esse sentimento: "a vida no crime não tem que ser motivo de orgulho para o meu filho, é motivo de vergonha. Se eu pudesse, eu queria que ninguém soubesse disso aí." Outros omitem o fato de estar preso para os filhos, conforme os estudos de Maldonado (2006) e McGrath (2007), com o intuito de preservar uma imagem positiva do pai ou para evitar a exposição da prole ao preconceito.

Dadas as dificuldades e limitações de contato físico entre sentenciados e familiares, as cartas parecem ser a estratégia mais viável e significativa para preencher essa lacuna, permitindo o compartilhamento de experiências que favorece o envolvimento afetivo de pais e filhos. O estudo de Hairston (2002) sublinha essa dupla função da correspondência, uma vez que assegura aos presidiários que não foram esquecidos, enquanto garante aos seus filhos a continuidade da experiência de ser amado. Esse recurso, ainda segundo a autora, também oferece aos pais a oportunidade de exercer um papel socialmente aceito, acompanhando o cotidiano dos filhos, oferecendo-lhes supervisão, apoio e encorajamento.

Um dos participantes falou sobre o exercício da paternidade à distância: “... eu não quero que meu filho tenha a minha vida, cometa os mesmos erros então eu preciso intervir... me fazer presente... o elo de ligação entre o pai e o filho é a carta!" (Tiago, Grupo A). O mesmo participante fez uso de uma metáfora para explicar o sofrimento claustrofóbico no cárcere: "as cartas são muito importantes para nós, são como envelopinhos de oxigênio, um momento para respirar". Reimar (Grupo C) completa: "a carta é a presença de quem não tem visita". Os demais participantes concordam que as cartas são o principal meio de comunicação com os filhos. Contudo, queixam-se da demora em chegar ao seu destino e da repercussão emocional gerada por essa situação: “...fica sem sentido e acabam prejudicando o relacionamento", diz Fábio (grupo C).

Confirmando os achados de Hairston (2001), Lee et al. (2012), Maldonado (2006), Mapson (2013) e Silva (2007) os relatos de nossos participantes indicaram que a manutenção do relacionamento entre pais encarcerados e seus filhos é benéfica para o bem estar de ambos, assim como para a instituição prisional e para a sociedade. Desta forma, evidenciamos que todos os envolvidos podem ser beneficiados, salvo quando as circunstâncias condenarem esse tipo de contato.

Há evidência na literatura científica (McGrath, 2007; Silva 2007; Swanson et al., 2012) e no relato de nossos participantes que os filhos podem ser o principal suporte emocional do preso nesta condição de vulnerabilidade, na medida em que atenuam as tensões e as privações da prisão: “... meu filho é que me dá força para aguentar o sofrimento que passo" (NI 13, Grupo A). Em outra narrativa (NI 2, Grupo D), o participante desabafa: "Pois você (dirigindo-se à filha) é meu refúgio neste lugar".

De uma perspectiva Winnicottiana, percebemos que a família do prisioneiro, sobretudo, os filhos podem oferecer um holding ${ }^{2}$ nesse momento de grande

\footnotetext{
2 A noção de holding na teoria winnicottiana refere-se à provisão ambiental inicialmente garantida pela mãe ao bebê, sendo gradualmente assumida pelo pai, pela família mais ampla e, finalmente, pela sociedade. Significa oferecer um ambiente que proporcione cuidado e sustentação emocional, trazendo segurança ao lactente e facilitando os processos de integração $\mathrm{e}$, consequentemente, o florescimento das potencialidades que carrega ao nascer (Winnicott, 1960/2007).
} 
vulnerabilidade, tornando-se o amparo e o conforto que o preso necessita para continuar existindo (Winnicott, 1960/2007). Já outro participante abordou os benefícios do contato íntimo entre pai e filho, na perspectiva do filho: "pai, sinto tanta falta do seu cheiro [...] ele gosta de ficar deitado no meu colo só para ficar sentindo o meu cheiro" (Marques, Grupo A).

Assim como Lanier (1993), encontramos nas produções narrativas dos participantes associações entre a manutenção do contato entre pais e filhos e o ajuste institucional do preso. Davi (Grupo C) explicou que, quando tem notícia dos filhos, consegue se alimentar e dormir bem. Outro referiu que "No sistema carcerário um contato com os filhos, com as mães, esposas, alivia, e muito, o dia a dia na prisão" (NI 4, Grupo A), acrescentando "outro item é o esforço que o pai fará para ter ótima conduta no sistema e pensar em sair logo da prisão e voltar a ter uma família".

Além do bem estar pessoal que o vínculo entre pai e filho promove a ambos, alguns relatos evidenciaram que os laços familiares podem se constituir como fator de proteção contra a reincidência criminal, fenômeno também observado por Codd (2008), Maldonado (2006) e Mapson (2013). Neste contexto, os filhos são vistos como os maiores incentivadores para a mudança de vida do pai, como nos mostra a NI 2, Grupo C: “... ela (a filha) é tudo para mim e por ela que eu mudei minha vida". E Tiago (Grupo A) reconheceu o valor protetor dos laços afetivos contra a reincidência no crime:

"Senhora, olha como a coisa funciona: se eu tiver minha família junto comigo, tendo sempre notícia deles, eu não vou encher o saco dele (do companheiro). Se ele me falar: vamos fazer um negócio na saidinha? Eu vou falar que não, porque eu penso no que eu tenho lá fora, e não vou sacrificar a confiança deles e, de repente, por tudo a perder de novo!"

Alguns participantes reconhecem a importância da presença paterna para o desenvolvimento saudável dos filhos, ilustrando as ideias de Winnicott (1960/2007) sobre a presença concreta dos pais, o que inclui a conduta paterna. Sem recusar a existência e o papel da fantasia inconsciente, Winnicott se detém sobre o cuidado que oferece as bases para a existência de um self pessoal e autêntico, cujas realizações ultrapassam os limites da fantasia. Alguns participantes refletiram sobre o lugar do pai: “... eu também sei que as crianças quando crescem sem nós, pais, crescem com sintoma de rebeldia" (Licurgo, Grupo D); ou nas palavras de Rubens (Grupo D), "É fato que a ausência do pai pode deixar o filho mais vulnerável ao mundo das drogas... e ao abuso, pois não tem ninguém para defender. A figura e a presença do pai, eu acho que é muito importante!"

O aprisionamento pode criar uma oportunidade para a reflexão pessoal do preso e a reavaliação de seus estilos de vida e de suas funções paternas, de acordo com os estudos de Arditti et al. (2005) e Clarke et al. (2005). Vários participantes relataram experiências transformadoras na prisão, por meio das quais passaram a valorizar o relacionamento com os filhos, o que é possível apreender pelo testemunho de Saul (Grupo B):

"Senhora, essa é uma receita que eu recomendo para todos no Brasil: se você não está sendo pai, vem preso que você vai saber ser! O mesmo para outras coisas, como comida, abraço... Você também começa a valorizar mais o tempo. O tempo não era aproveitado, e agora está sendo. Na rua eu ficava um pouquinho com minha filha e, às vezes, já corria para o bar... Aqui, até o grilo que canta a gente dá valor!"

Houve presidiários que reconheceram suas falhas e demonstraram o desejo de ser um pai melhor do que foram até o seu aprisionamento, o que é corroborado pela experiência profissional de uma das autoras na unidade prisional. Vários dos participantes expressaram sentimento de culpa e arrependimento tanto pelo estilo de vida que levavam, negligenciando suas responsabilidades como pai, como pelo impacto negativo do encarceramento sobre a vida dos filhos. Esses dados coincidem com os de Lanier (1995), sendo ilustrados pelas vinhetas a seguir:

“... sei que não tenho sido um pai presente [...] sei que um dos motivos de ele não estar aqui comigo é por causa dos meus erros que cometi no passado [...] Filho, me desculpe, mas fique sabendo que o pai te ama..." (NI 10, Grupo A)

"Em primeiro lugar me bateu uma grande saudade dela, e arrependimento por não ter dado o carinho $e$ atenção que ela merecia, devido eu ter sido pai muito novo e só queria ficar para a rua em busca de coisas erradas, eu não vi o crescimento dela, hoje me arrependo de tudo isso." (NI 2, Grupo C)

Além do sentimento de culpa e o arrependimento, o sentimento de impotência aflige muitos homens que estão separados de seus filhos pelo aprisionamento, pois limita suas possibilidades de exercer sua função de pai nos cuidados básicos de proteção, disciplina e apoio, além da provisão financeira à família. Con- 
forme Hairston (2002), a maioria dos presos acha que há muito pouco a ser feito pelos filhos quando se está na prisão: "O que é que eu estou podendo fazer aqui? Estou é dando despesa e preocupação para a família e ainda não ajudo em nada" (Davi, Grupo C).

Como Lanier (1993), também constatamos sentimentos depressivos em produções narrativas que enfatizam a dor da saudade dos familiares. Uma delas (Aníbal, Grupo D) revelou que muitos prisioneiros buscam o entorpecimento para anestesiar a dor que a ausência dos familiares provoca. Marques (Grupo A) disse que sua prisão teve um impacto enorme em sua vida e na de seus filhos: "Essa é a pior parte da cadeia para mim...o resto eu tiro de letra...". Este mesmo sentimento de perda está presente na NI 1 (grupo A): “... Ah, se esses muros e grades falassem o quanto é dura a dor de não recebê-los..."

Muitos pais encarcerados manifestam o receio de ser esquecido pelos filhos, ou substituído em sua função paterna (Hairston, 2001; Lanier, 1995; Mapson, 2013), fato que encontra justificativa diante do contato limitado entre pais e filhos, o qual deriva não somente de sua condição de prisioneiro, mas também da fragilidade dos laços que os vinculam às mães de seus filhos, além da falta de apoio institucional para o exercício da paternidade na prisão (Hairston, 1998). Fernando (Grupo C) reconheceu os riscos que a distância impõe: "Eu tenho muito medo que ele (o filho) me veja como um estranho", enquanto Eli (Grupo B) mostrou sua indignação diante do não reconhecimento; "meu filho começou a chamar o avô (se referindo ao avô materno) de pai. Acho que a mãe deles tinha que ter corrigido isso... O pai sou eu, ela tinha que falar: esse é o avô!"

Grande parte dos participantes mostrou-se preocupados com o envolvimento futuro dos filhos no mundo do crime e das drogas, repetindo a história paterna, como observa Silva (2007). Paradoxalmente, a mesma relação de confiança que se estabelece entre a criança e seu pai pode abrir caminho para que a imagem do pai criminoso se constitua como referencial de prestígio e poder. Alguns participantes esforçam-se para desmistificar a figura do herói-bandido: "Tento mostrar tudo que o pai passa nesse inferno: - Você quer vir parar nesse lugar? Então anda na linha!" (Miguel, Grupo A). Outros buscam ensinar ao filho o que aprenderam com a própria experiência: "eu não quero que meu filho tenha a minha vida, cometa os mesmos erros..."(Tiago, Grupo A).

Os participantes deste estudo teceram suas próprias teorias a respeito do papel do pai, referindo o impacto de uma relação conflituosa vivida com os próprios pais, seja por sua ausência, sua indiferença ou pela violência. Uma das narrativas (NI 6, Grupo A) ilustra o quanto a paternidade remete à relação com o próprio pai: “...p pois Carlos nunca tinha tido um pai. Foi criado por mãe solteira e prometeu para si próprio que se um dia fosse pai faria de tudo para ser o melhor pai do mundo!"

Esses relatos contundentes, dos quais aqui apresentamos uma pequena parte, dadas as restrições de espaço de publicação, levaram-nos a supor a possibilidade de estender o conceito de preocupação materna primária de Winnicott (1956/2000), que se refere ao delicado ajuste na sensibilidade materna às necessidades do filho, permitindo que estas sejam satisfeitas, para a experiência paterna que é resgatada, neste tempo suspenso da prisão, em que o pai é forçosamente levado a interromper sua vida, e pode refletir sobre erros e acertos, e sonhar com uma vida longe do crime e próxima da família. Seria legítimo falar de uma preocupação paterna primária que nasce do arrependimento, do medo e da solidão? $\mathrm{O}$ desejo manifesto de recuperar o tempo perdido seria mais uma estratégia de sobrevivência psíquica, ou uma autêntica intenção de resgate da relação com os filhos? Como não temos respostas para estas perguntas, encerramos o relato desta pesquisa com uma Narrativa Interativa (NI 6, grupo A) de um pai que sonha com a liberdade.

“... como era a vida dele quando estava solto, principalmente nesta data, que logo cedo era acordado pelo seu filho mais novo, que corria até seu quarto e pulava em sua cama, gritando feliz dia dos pais, com o desenho nas mãos, feito na escola, abraçava e falava: pai te amo muito, você é meu herói [...] Olha agora outra foto, essa foto é de suas meninas, suas filhas. Essas já são mocinhas, diferente do caçula. Essas, nessa data preferem fazer de conta que esqueceram que é o dia dos pais, isso deixava Carlos triste, mas no almoço vinham todas rindo e abraçando, dizendo: seu bobinho não esquecemos não, feliz dia dos pais, te amamos muito, papito!"

\section{Considerações Finais}

Devemos considerar que a expressiva participação dos presidiários como voluntários deste estudo não invalida a suposição de que outras expectativas, além da possibilidade de falar sobre o relacionamento entre pais e filhos possam ter alimentado essa disponibilidade, especialmente em razão da pesquisadora ser funcionária da instituição. Esse fato também pode ter influenciado as produções narrativas dos participantes, 
apesar da autora em questão ter observado uma grande espontaneidade tanto no preenchimento das histórias como nos grupos de discussão. Também podemos supor que os pais mais inclinados a participar voluntariamente desta pesquisa tenham sido aqueles que estavam mais ligados afetivamente a seus filhos, ainda que tivessem pouco ou nenhum contato com eles.

Tomar a paternidade no cárcere como objeto de pesquisa revelou uma lacuna surpreendente na literatura nacional, cujos raros trabalhos focalizam a experiência de mães presidiárias, o que nos levou a recorrer à literatura internacional e fazer um contraponto com a experiência paterna de prisioneiros. Embora seja reduzido o número de participantes em uma pesquisa qualitativa, nossos achados corroboram alguns dos resultados mais significativos de pesquisas estrangeiras, revelando vivências que são compartilhadas por prisioneiros de diferentes países de origem.

O encarceramento é um fator de risco para a manutenção dos laços entre pais presidiários e seus filhos, comprometendo o bem estar de ambos e a reintegração social do prisioneiro. Entretanto, vale ressaltar que para muitos a relação familiar conflituosa é anterior à reclusão, em função do estilo de vida paterno que caracterizava o período pré-encarceramento, sendo apenas agravada pela pena privativa de liberdade.

O presente estudo sinalizou os potenciais benefícios da preservação do vínculo entre pais encarcerados e seus filhos, bem como os fatores pessoais, familiares e institucionais que podem inibir ou facilitar a vinculação afetiva, na perspectiva do prisioneiro. Aqui, a noção ampliada de holding, a qual extrapola o ambiente familiar, vem iluminar algumas das vicissitudes da relação pai-filho, tão bem ilustradas pelos participantes deste estudo, na medida em que esta relação se mostra constantemente ameaçada pela falta de suporte social e possibilidades de expressão e realização no mundo. Conforme Winnicott (1960/2007), na falta de um ambiente de acolhimento, seja para o pai, seja para o filho, resta a reação, a defesa, a atuação. Não se trata de idealizar o pai prisioneiro, pois há casos em que o contato entre pais e filhos deve ser evitado, mas de repensar nossas práticas e preconceitos em relação à parentalidade e o ambiente necessário para o seu exercício.

Este estudo aponta para a necessidade de futuras pesquisas que venham ampliar e aprofundar o conhecimento sobre a paternidade no cárcere, considerando outras perspectivas desse fenômeno, ou mesmo outros pontos de vista, como o das companheiras e o dos filhos dos presidiários. É fato que a pesquisa sobre a paternidade é recente e que estudá-la em contextos específicos, como o presídio masculino, amplifica o que, em menor grau, observamos fora dele. Tal perspectiva oferece, a nosso ver, um rico contraponto para os estudos que focalizam a família e a sociedade como ambientes suficientemente bons para o desenvolvimento de seus membros.

Esperamos que o conhecimento adquirido com este estudo ofereça subsídios teórico-metodológicos para a atuação dos profissionais no sistema prisional, e possa inspirar a elaboração de novas práticas e a formulação de políticas públicas que visem minimizar os efeitos deletérios do aprisionamento através da proteção do vínculo entre pais e filhos, base para o bem estar da família e para a futura reintegração social do prisioneiro.

\section{Referências}

Arditti, J., Smock, S.A., \& Parkman, T. S. (2005). It's been hard to be a father: A qualitative exploration of incarcerated fatherhood. Fathering, 3(3), 267-288. http://dx.doi.org/10.3149/fth.0303.267

Boswell, G., \& Wedge, P. (2002). Imprisoned fathers and their children. New York: Jessica Kingsley Publishers. http:// dx.doi.org/10.1046/j.1365-2206.2002.t01-1-00258.x

Clarke, L., O’Brien, M., Day, R.D., Godwing, H., Connolly, J., Hemmings, J., \& Leeson, T. (2005). Fathering behind bars in English prisons: Imprisoned fathers identity and contact with their children. Fathering: A Journal of Theory, Research, and Practice about Men as Fathers, 3(3), 221-241. http://dx.doi.org/10.3149/fth.0303.221

Codd, H. (2008). In the shadow of the prison: families, imprisonment and criminal justice. London: Routledge

DEPEN (2015). Departamento Penitenciário Nacional. Disponível em: http://portal.mj.gov.br/data/Pages/ MJC4D50EDBPTBRNN.htm

Dyer, W. J. (2005). Prison, fathers and Identity: A theory of how incarceration affects men's paternal identity. Fathering: $A$ Journal of Theory, Research and Practice about Men as Fathers, 3(3), 201-219. http://dx.doi.org/10.3149/fth.0303.201

Edin, K., Nelson, T. J., \& Paranal, R. (2001). Fatherhood and incarceration as potential turning points in the criminal careers of unskilled men. In M. Pattillo, D. Weiman, \& B. Western (Eds.), Imprisoning America: The social effects of mass incarceration (pp. 46-75). New York: Russell Sage Foundation.

Goffman, E. (1982). Estigma: Notas sobre a manipulação da identidade deteriorada. Rio de Janeiro: Zahar. 
Granato, T. M. M. \& Aiello-Vaisberg, T. M. J. (2011). Uso terapêutico de narrativas interativas com mães em situação de precariedade social. Psico, 42(4), 494-502.

Granato, T. M. M. \& Aiello-Vaisberg, T. M. J. (2013). Narrativas interativas sobre o cuidado materno e seus sentidos afetivo-emocionais. Psicologia Clínica, 25(1), 17-35.

Granato, T. M. M. \& Aiello-Vaisberg, T. M. J. (2016). Interactive Narratives in the investigation of the collective imaginary about motherhood. Estudos de Psicologia, 33(1), 25-35. http://dx.doi.org/10.1590/1982-02752016000100004

Granja, R., Cunha, M. P., \& Machado, H. (2013). Formas alternativas do exercício da parentalidade: Paternidade e maternidade em contexto prisional. Ex aequo, 28, 73-96.

Hairston, C. F. (1998). The forgotten parent: Understanding the forces that influence incarcerated fathers relationship with their children. Child Welfare, 77(5), 617-639.

Hairston, C. F. (2001). Fathers in prison: Responsible fatherhood and responsible public policies. Marriage \& Family Review, 32(3-4), 111-135. http://dx.doi.org/10.1300/J002v32n03_07

Hairston, C. F. (2002). Prisoners and families: parenting issues during incarceration. In The from prison to home conference (pp. 42-54). Prepared for the Department of Health and Human Services by the Urban Institute: Washington, DC.

Houghton, A. J. M. \& Navarro, A. (2014). Incarcerated fathers and their children: effects of a reciprocally connected relationship. Electronic Theses, Projects, and Dissertations. California State University. http://dx.doi.org/10.1300/ J002v32n03 07

Lanier, C. (1993). Affective states of fathers in prison. Justice Quarterly, 10(1), 49-66. http://dx.doi.org/10. 1080/07418829300091701

Lanier, C. (1995). Incarcerated fathers: a research agenda. Forum on Correction Research, 7(2), 34-36.

Lee, C., Sansone, F. A., Swanson, C., \& Tatum, K. M. (2012). Incarcerated fathers and parenting: Importance of the relationship with their children. Social Work in Public Health, 27, 165-186. http://dx.doi.org/10.1080/19371918.20 12.629902

Maldonado, S. (2006). Recidivism and paternal engagement. Family Law Quarterly, 40(2), 191-211.

Mapson, A. (2013). From prison to Parenting. Journal of Human Behavior in the Social Environment, 23(2), 171-177. http://dx.doi.org/10.1080/10911359.2013.747402

McGrath, J. (2007). Fathering from prison: An exploration of the experiences and perceptions of a group of men in Montjoy prison. Doctoral dissertation. Waterford Institute of Technology, Waterford, Ireland.

Melo, S. de O. (2013). O impacto da reclusão na esfera familiar da vida dos indivíduos encarcerados. Dissertação de mestrado. Faculdade de Psicologia e Ciências da Educação. Universidade do Porto, Portugal.

Mumola, C. J. (2000). Incarcerated parents and their children. U.S. Department of Justice: Bureau of Justice Statistics. Washington, D.C. NCJ 182335.

Oliveira, G. V. (2010). Sanção penal e família: diálogos e possibilidades. Monografia apresentada ao Conselho Nacional de Política Criminal e Penitenciária - CNPCP por ocasião do Concurso Anual de Monografias.

Ormeño, G. R., Maia, J. M. D., \& Williams, L. C. A. (2013). Crianças com pais ou mães encarcerados: uma revisão da literatura. Journal of Child and Adolescent Psychology, 4(2), 141-161.

Silva, M. F (2007). Presidiários: percepções e sentimentos acerca de sua condição paterna. Dissertação de mestrado. Faculdade de Psicologia. Pontifícia Universidade Católica Campinas, São Paulo.

Stake, R. (2011). Pesquisa Qualitativa: estudando como as coisas funcionam. Porto Alegre: Penso.

Swanson, C., Lee, C., Sansone, F., \& Tatum, K. (2012). Prisoner's perceptions of father-child relationships and social support. American Journal of Criminal Justice, 37(3), 338-355.

Winnicott, D. W (2000). A preocupação materna primária. In D. W. Winnicott. Obras escolhidas: Da pediatria à psicanálise (pp. 399-405). Rio de Janeiro: Imago. (Original publicado em 1956).

Winnicott, D. W. (2007). Teoria do relacionamento paterno-infantil. In D.W. Winnicott. O ambiente e os processos de maturação (pp. 38-54). Porto Alegre: Artmed. (Original publicado em 1960).

\footnotetext{
Autores:

Tania Mara Marques Granato - Doutora, Pontifícia Universidade Católica de Campinas.

Endereço para correspondência:

Márcia Lepiani Angelini Miranda

Rodovia Jornalista Francisco Aguirre Proença, KM 4,5 - Jd Novo Angulo

Caixa Postal 29

13185-901 Hortolândia, SP, Brasil

<mlangelinim@yahoo.com.br>

Recebido em: 15.02 .2016

Aceito em: 22.06.2016
}

Márcia Lepiani Angelini Miranda - Mestranda, Pontifícia Universidade Católica de Campinas. 